\title{
Entrepreneurship and Crowdfunding in Lebanon: ABC Model of Attitude
}

\author{
Lena Saleh $^{1} \&$ Amar Kinaan ${ }^{1}$ \\ ${ }^{1}$ Lebanese University, Faculty of Economic \& Business Administration, Beirut, Lebanon \\ Correspondence: Lena Saleh, Lebanese University, Faculty of Economic \& Business Administration, Beirut, \\ Lebanon.
}

Received: November 26, 2020

doi:10.5539/ibr.v14n1p119
Accepted: December 16, 2020 Online Published: December 28, 2020

URL: https://doi.org/10.5539/ibr.v14n1p119

\begin{abstract}
In light of insufficient traditional methods of funding of entrepreneurial projects and ventures in Lebanon, crowdfunding is proposed as an alternative funding mechanism. Crowdfunding is a way for entrepreneurs to fund their projects via dedicated online platforms where the needed capital is accumulated from small contributions from a large number of interested individuals: the crowd. Since the people are at the center, it is vital to address their attitudes toward participating as funders. For this aim, the researcher derives from previous studies and the present literature a conceptual framework that proposes to explain what impacts attitudes toward participating as funders in crowdfunding. The model is tested via a questionnaire targeted to 457 workers located in the four main regions of Lebanon. Results of the statistical analysis confirmed the proposed model and confirmed 3 out of 4 of the hypotheses pertaining to the variables (enthusiasm, trust, and experience) and gave insights concerning awareness, understanding, and attitudes regarding crowdfunding in Lebanon. The study provides recommendations for improvement of the status of crowdfunding in Lebanon for the benefit of entrepreneurs, SMEs, and the economy.
\end{abstract}

Keywords: entrepreneurship, crowdfunding, attitudes; enthusiasm, trust, experience, knowledge, Lebanon

\section{Introduction}

Entrepreneurship is becoming one of the most studied concepts drawing interest of scholars and researchers worldwide for its role in economic health and growth. In the face of uncertainty, challenges, and obstacles, an entrepreneur sees opportunity and a chance to solve a problem (Scarborough, 2011). Entrepreneurs in Lebanon face a major issue when it comes to starting up their ventures. Great difficulties and challenges arise in many arenas especially in acquiring the needed capital for launching their small and medium enterprises (SMEs). Crowdfunding is a relatively new phenomenon that is increasing in popularity in different aspects of the world and showing potential for sufficient funding of well-designed entrepreneurial business ideas and projects. Crowdfunding is an Internet-enabled way for businesses or other organizations to raise money in the form of either donations or investments from multiple individuals (World Bank, 2013). In one Fortune magazine article, Noyes (2014) described the process of crowdfunding as "democratizing fundraising". This is because the people are the ones who decide which product reaches the market resembling presidential elections. Crowdfunding can help entrepreneurs to find investors for their projects all over the world because crowdfunding is not limited to a specific geographical region. The principle of crowdfunding is supported by world-wide networks that can connect entrepreneurs and investors from everywhere. All crowdfunding processes are implemented on crowdfunding websites (platforms), which usually include high level of business flexibility. While this method is becoming well-developed in regions like the US, Australia, and Europe, it is still in its early phases in the Arab world, particularly Lebanon, though blooming and showing potential for growth. Though the idea of crowdfunding is growing and gaining more popularity in Lebanon, it is still considered in its infancy and needs more development in the market to well-serve Lebanese entrepreneurs' needs. Furthermore, while studies tried to capture attitudes and motivations of funders, there has not been one specific conceptual framework with clear variables that attempts to explain individual attitudes toward participating as funders in crowdfunding, especially in Lebanon. Thus, the general problematic of this research is to explain the factors that shape and impact individual attitudes toward participating as funders in crowdfunding. From this basis, it is attempted to understand the relation between four independent variables (enthusiasm, trust, experience and knowledge) and 
the dependent variable (individual attitudes toward participating as funders in crowdfunding). Furthermore, the aim of this paper is to understand Lebanese individuals' position toward crowdfunding, whether they are aware, whether they understand, and whether they have positive attitudes toward this new funding mechanism. For this purpose, the researchers adopts a constructivist ontological position.

\section{Entrepreneurship and Crowdfunding}

\subsection{Challenges Faced by Lebanese Entrepreneurs}

A report issued by Inventis (a strategic advisory and management consulting firm) gave great insight into the status of entrepreneurs and SMEs in Lebanon ${ }^{1}$. Furthermore, as reported by the Global Entrepreneurship Monitor (an international collaborative research program designed to measure levels of entrepreneurship, using consistent definitions and survey methods that allow carrying out meaningful comparisons between countries, and between years), Lebanon holds a high rate of entrepreneurial activity spanning approximately $15 \%$ of the population aged between 18 and 64. This can lead to the conclusion that Lebanon is an encouraging atmosphere for early stage entrepreneurial activity. Attributed to this high percentage are several things including the well education of the Lebanese youth, the country's cultural values of liberalism, and the somewhat superiority of the private sector in the country. The challenges Lebanese entrepreneurs face when going after their entrepreneurial endeavors have many faces. First, due to political struggles and wars, Lebanon has comparably poor infrastructure. This causes an increase in the costs of operation for SMEs as they have to bear costs of privatization of utilities such as water and electricity (AlHussaini \& Hill, 2017). Second, the political instability that still causes tension in the Lebanese economy has made it hard for entrepreneurs to make long term plans and investments (Inventis, 2014). Third, concerning the legal environment, some difficulties still arise though the Lebanese government has initiated programs and laws including cut-offs on tax and tariff for entrepreneurs. However, effort must be exerted to properly execute such laws and incentives. Entrepreneurs face high costs and difficulties with trade regulations and customs. Though support initiatives have risen to aid entrepreneurs and support their businesses, awareness of these moves is still limited. Another disadvantage for entrepreneurs is the red tape and bureaucracy that affects SMEs more than larger counterparts (Ministry of Economy and Trade, 2013). A further challenge is the uncertainty the Lebanese economy is facing. Businesses have been slowing down, making it seem more challenging for SME prospects. This is added to the perceived corruption and the lack of government support (AlHussaini \& Hill, 2017). Next, it is a challenge for entrepreneurs to have successes in a market with great levels of local and global competition as well as an empowered and dynamically demanding consumer base (Inventis, 2014). Finally, according to the Ministry of Economy and Trade (2014), entrepreneurs and SMEs suffer from weak financial and monetary power, the thing that makes it hard for them to battle and overcome the aforementioned challenges leaving them at a weaker state than larger competitors.

\subsection{Challenge of Funding}

Filion (2011) stated that to define entrepreneurship, it is important to understand its main constituents which include locating opportunities, managing risk, creativity, agility, clever use of resources, and the added value to be brought to the work. He describes the entrepreneur as a clever artist who paves new ways for value creating business and utilizes the assets and skills needed for its development. In Lebanon, SMEs, representing entrepreneurial ventures, make up about $90 \%$ of total Lebanese enterprises population, as reported by the Ministry of Economy and Trade (2014).

Financing a venture and its needed capital have long been of the main worries entrepreneurs must face in starting their ventures. A study in Sub-Saharan Africa by Legas, (2015), investigated the challenges entrepreneurs confront in wanting to start their businesses. The biggest hurdles, as shown by entrepreneurs, had to do with finding proper funding and competing with large established firms. Not only is financing necessary for establishment of firms, it is vital for their growth and success. Otherwise, firms may turn to lending which is paired with high demands of collateral from investors (Legas, 2015). A starting capital is crucial for someone to become an entrepreneur launching his/her project or venture. A study in Kenya showed that acquiring this needed capital is one of the main obstacles and challenges entrepreneurs face. That is because banks require hard-to-achieve conditions to provide loans that are not feasible to everyone (Kaburi et al., 2012). Thus, from the preceding, it may be concluded that one of the first issues to be discussed when an entrepreneur wants to execute a new idea and start a new venture is the source of capital to be used. Access to loans from financial institutions

\footnotetext{
${ }^{1}$ In defining SMEs in Lebanon, both measures are considered (number of employees and yearly turnover). To qualify as an SME in Lebanon, first, the number of employees must be less than 100 and second, with a yearly turnover of less than 25 billion Lebanese pounds (around 16 million USD) (Inventis,2014)
} 
isn't always easy and convincing investors to put cash into risk for a new start-up can be a tiring, costly, and long process.

In Lebanon, though the financial sector is well-figured, funding seems to be one of the issues that the country faces. The Lebanese economy is debt-driven and there is an obvious mismatch in supply and demand of capital for SMEs. Furthermore, the government does not support SMEs enough to aid them into prosperity (Sardouk \& Dorant, 2015). Thus, SMEs have a hard time acquiring funding and resort to financial institutions ${ }^{2}$.

\subsubsection{Defining Crowdfunding}

Crowdfunding, coined less than twelve years ago, is still considered a relatively new technique. Academic literature on the subject is still in its primary phases, even though crowdfunding has caught major attention internationally over the past few years. This attention was a result of the successes of popular crowdfunding platforms for entrepreneurs who faced difficulties obtaining capital from more traditional sources of funding (Dehling, 2013).

The growth of crowdfunding has been linked to, for starts, the growth of the Internet. People being more easily linked to people means investors more easily linked to investees. Added to that is the financial crisis the world witnessed in 2008, stressing on the aforementioned difficulty for entrepreneurs obtaining funds in traditional ways (Kuti and Madarasz, 2014).

Over the years, crowdfunding has caught major attention from fund seekers who strive to innovate, grow, and develop, as well as attention from funders (supporters or investors) who seek, among other things, social gain and benefits when allotting their money through a crowdfunding Internet platform. Recently, crowdfunding has become a dynamically expanding financing method worldwide, especially when talking about Europe, Australia, and the United States (Kuti and Madarasz, 2014).

Examples and stories on crowdfunding show that this relatively new technique in financing is becoming a complement, or even a substitute for traditional forms of funding. Mollick (2013) signifies that crowdfunding can be, in addition to being a funding mechanism, a way for entrepreneurs to understand demand for their products/services which could help provide them with traditional methods of financing.

Crowdfunding has been growing swiftly, for the ease and simplicity for founders to coordinate and cooperate with stakeholders. It has drawn the attention of a variety of entrepreneurial fund seekers ranging from for-profit, cultural, or even social projects to present their campaigns to the crowd and seek out funding, often in exchange for products or equity (Poetz \& Schreier, 2012).

Crowdfunding, as a way of funding, is derived and inspired by several concepts in finance like micro-finance (Morduch, 1999) and crowdsourcing (Poetz \& Schreier, 2012). However, crowdfunding stands out as a unique method of financing making use of the Internet via special platforms.

To define crowdfunding appropriately in this research, the entrepreneurial framework must stay in mind. Crowdfunding can be referred to as "the efforts by entrepreneurial individuals and groups - cultural, social, and for-profit - to fund their ventures by drawing on relatively small contributions from a relatively large number of individuals using the Internet, without standard financial intermediaries" (Mollick, 2013). This definition explains simply the dynamics of crowdfunding where it is based on the idea of collecting small amounts of money from a large number of people to make up the needed capital for different types of entrepreneurial ventures, whether business, social, cultural, or other. The definition also focuses on the fact that this method of funding can be an alternative to rather tough to acquire traditional methods of funding such as banks, venture capital, angel investors, etc.

Crowdfunding can also be defined as "an open call, essentially through the Internet, for the provision of financial resources either in form of donations or in exchange for some form of reward and/or voting rights in order to support initiatives for specific purposes (Schweinbacher \& Larralde, 2010). This definition focuses more on the types of crowdfunding which will be introduced in the next part. It provides the goals of founders as well as

${ }^{2}$ Acquiring loans from banks is a difficult mission since banks have a hard time trusting new and emerging SMEs with risky business ideas and little to no business history. Hard terms and conditions are applied including feasibility studies and evidence for targeted market existence in addition to the need for cash or property collateral or a personal guarantee. In fact, the share of loans given to SMEs was only $16 \%$ in 2010 which is significantly lower than 26\% in developed countries (Ministry of Economy and Trade, 2013). Moreover, banks only provide a portion of the needed capital and not the whole amount and the amounts granted for entrepreneurs do not exceed 200,000 USD. 
funders and the benefits and advantages of each. It also focuses on the role of the Internet in enabling this exchange relationship. Finally, crowdfunding is described as an open call indicating that it is of vast range not limited to a small geographic area or a certain targeted group of individuals. Rather, crowdfunding is addressed to anyone and everyone who would be interested in the idea or project.

Kraus et al. (2016) identify four models for crowdfunding (types of crowdfunding) which are identified as follows in the table below.

Table 1. Existing Models of Crowdfunding (Kraus et al., 2016)

\begin{tabular}{|l|l|}
\hline Crowdfunding Model & Description \\
\hline Reward Based & $\begin{array}{l}\text { Founder receives contributions from crowdfunders and rewards them with early } \\
\text { issue of product or anything else }\end{array}$ \\
\hline Donation Based & Founders get donations from crowdfunders for the start-up of community benefit \\
\hline Equity Based & Founder offers ownership or equity to funders in return for their investment \\
\hline Lending Based & $\begin{array}{l}\text { Founder borrows money from crowdfunders and gives them future repayment of a } \\
\text { principal with or without interest }\end{array}$ \\
\hline
\end{tabular}

\subsubsection{Emerging Theories on Crowdfunding}

Crowdfunding has had a wide array of research on its dynamics, motivations, history, advantages, and success factors. This has led to gaining more understanding of this concept paving the way for understanding individuals' attitudes about it.

Some of the most relevant researchers in the field include: Belleflamme, Agrawal, Schienbacher, and Mollick.

Belleflamme et al. (2011), in his pursuit to define crowdfunding, states that one of the main building blocks of the term is the "crowd"; a big number of people giving very small contributions and not a small number of sophisticated investors providing the investment amount. In another research, he, along with Kleeman in 2008, stressed the role of the Internet in its many platforms such as Facebook, Twitter, LinkedIn, Kickstarter, and other blogs.

Schwienbacher and Larralde (2010) gave insights into different issues that may originate during the crowdfunding process. They introduce crowdfunding, define it, and give a description of the different factors that influence an entrepreneur's decision when choosing to crowdfund. This includes the already-available resources, risk, information asymmetry (with the investors), ethics, organizational form, control, amount required, and legal issues. The authors provide a real-world example of a French startup (Media Nomad) that successfully exploited the crowdfunding process to fund a website devoted for travelers sharing their experiences and recommendations. In the process, they ended up raising more than just capital, but also skills and an active enthusiastic community that helped get the project done and in its best shape.

Agrawal et al. (2011) were interested in the geography of crowdfunding and whether the distance between entrepreneurs and backers made a difference and they found out that it does, to a certain extent. They found that crowdfunding did reduce the impact of distance and geography compared to traditional funding. However, backers were shown to be more committed to close projects and entrepreneurs and invested in them earlier than those from a distant area.

Mollick (2013) aimed at giving a clearer picture of crowdfunding and giving, for the first time in the literature, an understanding of the dynamics of crowdfunding. In his study, he found that crowdfunding projects' success is related to quality, network, preparedness, being featured, as well as pledge levels. He also found that projects tend to fail or succeed by large margins He suggests that geography may play an important role in the success of crowdfunding efforts, especially in relation to culture where founders and funders of similar interests are sometimes aggregated in the same areas (for example, a project on country music founded by and funded by people around Nashville, Tennessee). Finally, addressing the risk factor, he found that projects do deliver their promised merchandise or gifts, though sometimes at delay caused by project size and excess demand and popularity than expected.

Kuppuswamy and Bayus (2013) explain backers' behavior in crowdfunding campaigns where backers get to see the level of support a project is getting as well as the deadline to the campaign. They suggest that social information (decisions of others) will impact an individual's own decision regarding if and when to fund a project.

An important concept in crowdfunding is "the wisdom of the crowd", this was discussed by Howe (2008), Brabham (2008), and Surowiecki (2006). The authors state that the aggregate efforts of individuals together 
create better solutions than of individuals alone and that crowds could be more efficient than individuals or small teams. In addition, the more diverse a group is, the more efficient it can be.

\section{Research Methodology}

\subsection{A Conceptual Framework and Hypotheses Statement}

For the purpose of understanding individual attitudes toward participating as funders in crowdfunding, the researcher developed a conceptual model that includes four variables (enthusiasm, trust, experience, and knowledge) said, in previous studies (Belleflamme et al., 2011; Oxera, 2015; Moon \& Hwang, 2018), to influence attitudes toward participating as a funder in crowdfunding. The conceptual model was developed from the ABC model of attitudes (Breckler, 1985). The ABC model of attitudes divides attitudes into three components: Affect, Behavior, and Cognition. These three components are referred to as verbs "feel, do, and think". "Affect" is an individual's emotions and feelings toward a subject. "Behavior" represents intentions, verbal statements related to behavior, and actual action. "Cognition" concerns knowledge and beliefs. These three components have a close relationship with each other and affect an individual's attitude toward a subject. Thus, "Affect" is represented by enthusiasm and trust. "Behavior" is said to be experience. And finally, "Cognition" is represented by knowledge. The conceptual model is shown in figure 1 below.

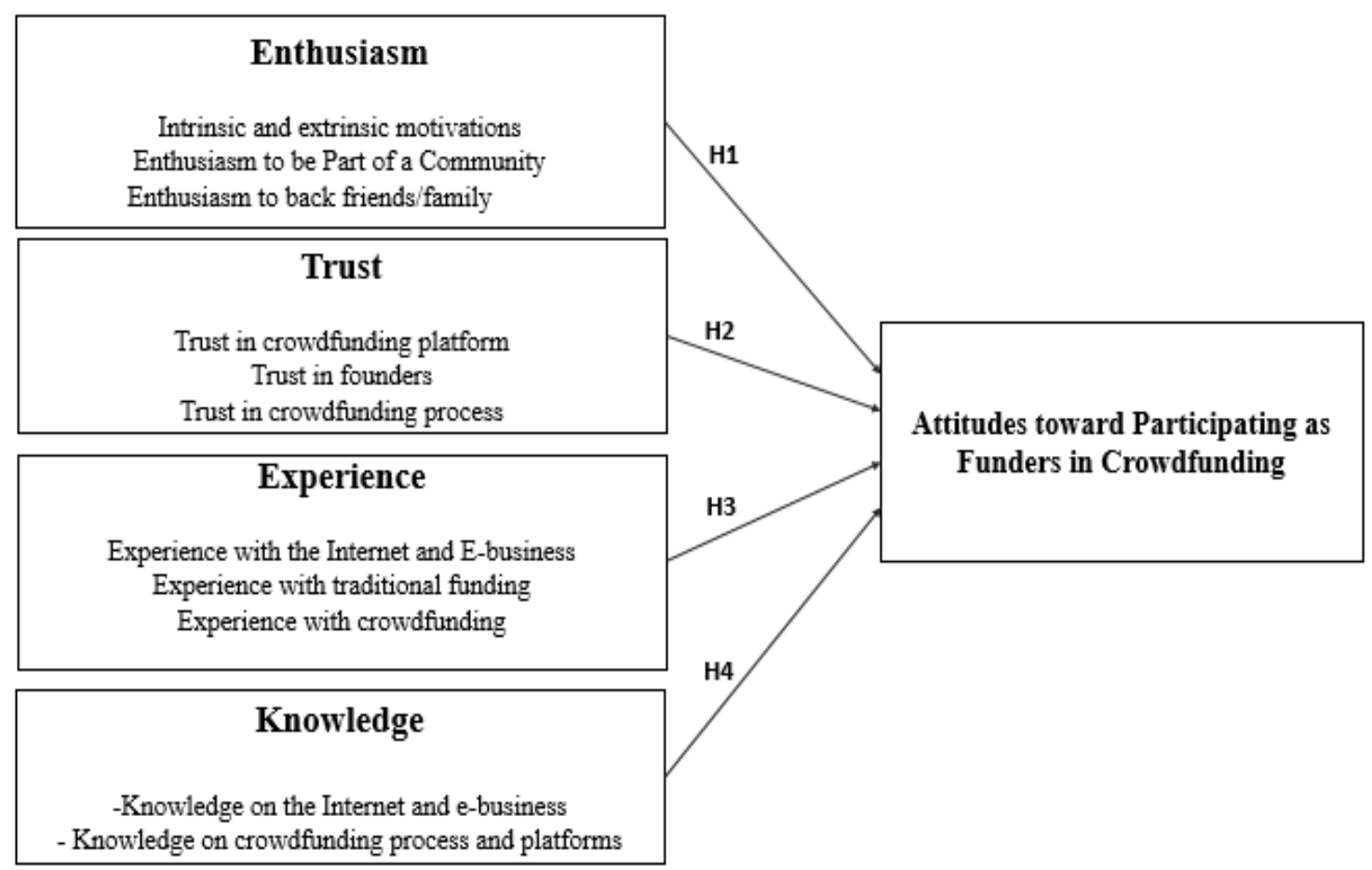

Figure 1. Conceptual Framework: Factors Influencing Attitudes toward Participating as Funders in Crowdfunding

The hypothesis statements were as follows:

Hypothesis 1: Enthusiasm has a positive impact on attitudes toward participating as funders in crowdfunding.

Hypothesis 2: Trust has a positive impact on attitudes toward participating as funders in crowdfunding.

Hypothesis 3: Experience has a positive impact on attitudes toward participating as funders in crowdfunding.

Hypothesis 4: Knowledge has a positive impact on attitudes toward participating as funders in crowdfunding.

\subsection{Sample Industry}

The questionnaire was sent out through the Internet to reach individuals from different areas such as Beirut, North Lebanon, South Lebanon, and Beqaa. A non-probability virtual snowball sampling method was employed since the target was a large number of working individuals in all types of organizations, all ages, and both genders. The number of responses received was 468 . Out of these, 11 questionnaires were rendered unviable due to incomplete information whether in the demographics section or in the questions section. The resulting sample 
size after removing the unviable questionnaires was 457.

\subsection{Design of the Questionnaire}

For the first independent variable, enthusiasm, the questionnaire contained four items (i.e. liking innovative products, interest in project, being part of a community, and supporting friends and family). The second independent variable, trust, contained three items (i.e. trust in project founders, trust in platforms, and trust in crowdfunding process). As for the third independent variable, experience, the questionnaire had three items (i.e. experience with the Internet, experience with traditional funding, and experience with crowdfunding). Finally, the last independent variable, knowledge, included four items in the questionnaire representing it (i.e. knowledge in the Internet and e-business, heard term crowdfunding, understand crowdfunding, and knowledge of platforms). The dependent variable, attitude toward participating as funders in crowdfunding, was represented and measured by four items (i.e. belief if crowdfunding can be a success, positive attitude, likelihood to become a backer, and likelihood to become a founder).

\section{Results}

\subsection{Studying the Homogeneity of the Metric Scales}

The first homogeneity test of the metric scales concerns validity. Validity explains how well the collected data covers the actual area of investigation (Ghauri and Gronhaug, 2005). In other words, the research instrument actually measured what it was supposed to measure. To measure the validity of the research instrument (the survey), the researcher operates factor analysis which is a method that aims at evaluating the items of a scale and the relationships among each other in order to rule out irrelevant items from the scale. This is done to ensure that all items of a scale measure what they intend to measure before applying inferential statistics. In other words, the questions asked relate to the construct needed to be measured. As a result of Factor Analysis, any items that did not contribute significantly enough to the dimension were eliminated, or otherwise, retained. In the study of factor analysis, two measures will first be displayed: the KMO (Kaiser-Meyer-Olkin) (Kaiser, 1974) and Bartlett's test of Sphercity (Bartlett, 1937). An ideal KMO is that close to 1 indicating a high degree of significance. A resulting value less than 0.5 would be deemed unacceptable. Considering Bartlett's measure, a resulting value less than 0.05 would be considered significant. This test indicates if the variables in the correlation matrix are correlated significantly different than 0 using an indicator of $(p<0.0001)$.

The second part of the homogeneity tests of the metric scales is reliability tests. Reliability is concerned with the extent to which a measurement of a phenomenon provides stable and consistent results (Carmines and Zeller, 1979). In other words, a research instrument is said to be reliable if it provides the same results if the measurement is repeated with the same conditions. One of the most common measures of internal consistency is the Cronbach Alpha coefficient (Cronbach, 1951), especially when Likert scale is utilized in the study. The desired coefficient for each variable in this study is considered to be at a minimum of 0.7 (Whitley, 2002).

In the table below, the researcher has synthesized the set of items selected as a result of the factorial analysis (PCA and Chronbach $(\alpha)$ carried out on the different variables.

Table 2. Summary of the variables and items selected as a result of the factorial analysis

\begin{tabular}{|l|l|}
\hline Variable & Items Selected \\
\hline Enthusiasm & Like Innovative Products \\
\cline { 2 - 2 } & Support Interesting Projects \\
\cline { 2 - 2 } & Part of a Community \\
\cline { 2 - 2 } & Supporting Friends and Family \\
\hline \multirow{4}{*}{ Erust } & Trust Platform \\
\cline { 2 - 2 } & Trust Founders \\
\cline { 2 - 2 } & Deliver Rewards \\
\hline \multirow{4}{*}{ Knowledge } & Funded Traditionally \\
\cline { 2 - 2 } & Funded Crowdfunding \\
\hline \multirow{4}{*}{ Attitude } & Heard Term Crowdfunding \\
\cline { 2 - 2 } & Understand Crowdfunding \\
\cline { 2 - 2 } & Know Platform \\
\hline & Crowdfunding can be a success \\
\cline { 2 - 2 } & Positive Attitude toward Crowdfunding \\
\cline { 2 - 2 } & Participate as Funder \\
\cline { 2 - 2 } & Participate as Founder \\
\hline
\end{tabular}




\subsection{Regression Analysis}

The multiple regression analysis test was chosen to understand the relations between each independent variable and the dependent variable. Multiple Linear Regression illustrates several variables' relationships with a dependent variable explaining which variable has the strongest and most significant impact (Salleh, Zainudin, \& Arif, 2017). The analysis used a confidence interval of $95 \%$ for the coefficients.

The results of the multiple regression test presented in Table (3) show an $\mathrm{R}$ value of 0.865 , also connoted as $86.8 \%$, indicating a strong correlation between the predicted and the observed values in the outcome variable. The adjusted $\mathrm{R}^{2}$ had a value of 0.749 meaning that approximately $74.9 \%$ of the total variability in the outcome variable is the result of the model with its four predictor variables. Furthermore, checking the p-values, which should be less than 0.05 to have significant impact, three variables were found to coincide with this criterion while one variable didn't. The p-value for enthusiasm and trust was 0.000 dramatically less than 0.05 . In addition, experience showed an acceptable value of 0.003 which agrees with the specified threshold. This shows that each of the three variables enthusiasm, trust, and experience offers a significant amount of unique variance in the dependent variable that other variables do not offer. On the other hand, the p-value of the last independent variable, knowledge, showed a result of 0.057 which is slightly above the acceptable p-value meaning that this variable does not offer a significant amount of unique variance in the dependent variable. Therefore, it is not a significant predictor of attitudes in this model. The four variables enthusiasm, trust, experience, and knowledge presented coefficient of $0.367,0.403,0.040$, and 0.055 respectively. The constant (intercept) coefficient for when all the variables are zero was 0.785 . This results in the following equation (1) for multiple linear regression

Equation 1: Regression Equation of Independent Variables Enthusiasm, Trust, Experience, and Knowledge with Dependent Variable Individual Attitudes

Attitudes $=0.368($ Enthusiasm $)+0.403$ (Trust $)+0.04($ Experience $)+0.055($ Knowledge $)+0.785$

It is noticeable that enthusiasm and trust have relatively higher coefficients in the multiple linear regression equation and thus stronger impact on the dependent variable than do experience and knowledge. This result is translated in the statement that each increase of 1 unit in the variable enthusiasm results in an increase of 0.367 in attitude and each increase by 1 unit in the variable trust results in an increase by 0.403 in individual attitudes. It is likewise for the other two variables.

Thus, it can be seen that when the independent variables are paired together, two variables stand out with a noticeably stronger impact on the dependent variable (enthusiasm and trust) than the other two variables (experience and knowledge). And while the independent variable "knowledge" had a significant impact when tested alone in simple linear regression, it showed no significant impact when paired with the other three variables. This result might be attributed to the fact that "Experience" actually includes "Knowledge" in it. To have experience, a minimal level of knowledge must be existent. This is not the case conversely since knowledge can be taught with no needed practical execution or experience. Thus, for example, those who answered they had experience with the Internet automatically had sufficient knowledge about the Internet. Therefore, in this model, part of the variance accounted for knowledge was also accounted for experience. This led to a low and insignificant level of unique contribution of the independent variable knowledge. Being an insignificant predictor in multiple linear regression, thus, made knowledge an insignificant predictor of attitudes overall. This lead to the acceptance of the hypotheses $\mathrm{H} 1, \mathrm{H} 2$, and $\mathrm{H} 3$ pertaining that enthusiasm, trust, and experience (respectively) have a positive impact on attitudes toward participating as funders in crowdfunding. Furthermore, this result leads to the rejection of $\mathrm{H} 4$ pertaining that knowledge has a positive impact on attitudes toward participating as funders in crowdfunding. The rejection of this hypothesis does not mean knowledge has no impact at all, but rather the impact might be included in the variable "experience" (knowledge is a part of, and a prerequisite for, experience). From this multiple linear regression, it was learned that enthusiasm and trust were the strongest predictors of the dependent variable followed by experience. Knowledge had an insignificant impact in this model. Nevertheless, the results of the model still showed a high and significant $\mathrm{R}^{2}$ value, even though some of the independent variables proved insignificant indicating that the model overall in all its variables well-predict the dependent variable.

The corresponding results are presented in table (3) below. 
Table 3. Results of Multiple Regression Analysis

\begin{tabular}{|c|c|c|c|c|c|}
\hline \multicolumn{6}{|c|}{ Model Summary } \\
\hline Model & $\mathrm{R}$ & \multicolumn{2}{|c|}{ R Square } & \multicolumn{2}{|c|}{ Adjusted R Square } \\
\hline 1 & \multirow[t]{2}{*}{0.865} & \multirow[t]{2}{*}{0.749} & & 0.747 & \\
\hline \multicolumn{4}{|l|}{ Coefficients $^{\mathrm{a}}$} & & \\
\hline \multirow[t]{2}{*}{ Model } & \multicolumn{2}{|c|}{$\begin{array}{l}\text { Unstandardized } \\
\text { Coefficients }\end{array}$} & $\begin{array}{l}\text { Standardized } \\
\text { Coefficients }\end{array}$ & \multirow[t]{2}{*}{$\mathrm{T}$} & \multirow[t]{2}{*}{ Sig. } \\
\hline & $\mathrm{B}$ & Coefficients & Beta & & \\
\hline (Constant) & .785 & .093 & & 0.8441 & .000 \\
\hline Enthusiasm & .367 & .029 & .426 & 12.449 & .000 \\
\hline Trust & .403 & .029 & .469 & 13.688 & .000 \\
\hline Experience & .040 & .023 & & 2.621 & .003 \\
\hline Knowledge & .055 & .021 & $\begin{array}{l}.076 \\
.080\end{array}$ & 2.663 & .057 \\
\hline
\end{tabular}

a. Predictors: (Constant), Enthusiasm, Trust, Experience, Knowledge

b. Dependent Variable: Individual Attitudes

\section{Discussion}

Results demonstrated that there is a low level of awareness in Lebanon of this relatively new method of funding: Crowdfunding. The Lebanese people, as the sample suggested, had low awareness of the topic to form well-informed attitudes. It was also seen that there are relatively low levels of understanding of the topic for a great portion of those who are crowdfunding-aware. This may be linked to the discouragement of the Lebanese to indulge in online activities that go beyond entertainment (El-Amine, 2017). Despite the efforts encouraging e-commerce and online activity in business, most of the Lebanese people still prefer to do their business offline and present mistrust to online activity (especially if it involves e-payment). And since crowdfunding is not studied in many curriculums in schools or universities, it was expected to have low awareness of this idea. On the other hand, while awareness was minimal, results showed a positive outlook for the future since participation level was high in the small portion of crowdfunding-aware individuals. Thus, proper awareness and improving attitudes can go the long way in making crowdfunding a viable and successful method of funding entrepreneurial projects. Considering current attitudes, the researcher tested the proposed model through simple and multiple linear regression. The three hypotheses pertaining that enthusiasm, trust, and experience were approved meaning that these variables have an impact on attitudes toward participating as funders in crowdfunding. The hypothesis pertaining that knowledge has a similar impact was rejected and that was attributed to the inclusion of its impact in the variable "experience". The extensive analysis of the results showed that enthusiasm and trust contributed the most to attitudes toward participating as funders in crowdfunding. Enthusiasm was mentioned in a great number of publications about crowdfunding, sometimes referred to as intrinsic motivations (Schwienbacher \& Larralde, 2010) or feelings of enjoyment or excitement (Oxera, 2015). Community benefits (Belleflame, 2011) and support for friends and family (Agrawal, 2011) were major parts of the variable enthusiasm which showed great impact on attitudes toward funding crowdfunding projects. In each of the mentioned studies, enthusiasm was shown to be of the greatest impact on attitudes and behavior compared to other motivations which are reinforced by this study. Thus, when enthusiasm toward a project exists, it is quite likely to have active participation in crowdfunding it. This was demonstrated in the graph of the regression line between the two variables where enthusiasm was a good predictor of attitudes. When enthusiasm is strong, a positive attitude is predicted and the opposite is true. Observing Lebanese crowdfunding platforms (such as Zoomaal), it is noticed that a great percentage of projects in general, and funded projects especially, are those relating to donation for causes (health, environmental, social, etc.). Thus, the emotional aspect can be seen as the dominant factor defining people's attitudes toward participating as funders in crowdfunding. The second highly correlated independent variable, trust, showed similar results upon simple linear regression. Trust was a major factor in influencing individuals' attitudes toward crowdfunding in multiple readings (Oxera, 2015; Kuti \& Madarász, 2014; Belleflame, Lambert, \& Schwienbacher, 2011; Moon \& Hwang, 2018; Gerber \& Hui, 2014). Regression analysis showed a great impact of trust (in crowdfunding projects, platforms, founders, and the whole process) on the making up of the opinion and attitude of individuals toward participating as funders in crowdfunding. This result is in line with the result of hypothesis testing of Moon and Huang (2018) by which it was shown that perceived trust affected the user's intention, meaning a positive attitude toward being a crowdfunder. This result was well-predicted considering that trust is an important element for building a prosperous relationship between funders and project founders (Ng et al., 2016). Furthermore, trust is necessary to mitigate worries about fraud and failed projects (Alegre \& Moleskis, 2016). Thus, trust is a primary element in building positive attitudes toward crowdfunding entrepreneurial projects. This is especially important to note in the Lebanese culture where 
it is noticed that the Lebanese have comparably low levels of trust toward online business transaction especially those concerning online payment (El-Amine, 2017). The weak positive levels of trust were matched with weak positive attitudes toward crowdfunding. Though improving through generations, Lebanon is still considered lagging on e-business with one of the biggest reasons is mistrust of online activity and a perceived lack of secure online payment. Thus, it is no surprise to have relatively insufficient trust in crowdfunding being an online activity requiring online payment. The third independent variable, which also showed an impact on shaping attitude toward crowdfunding, though in slightly less effect, is experience in the Internet, traditional funding, and crowdfunding. It was proposed that having previous encounters with the aforementioned promotes a positive attitude stronger than of those with no experience at all. The fourth variable, knowledge, showed a positive significant impact in simple linear regression, though weaker than the impact of enthusiasm and trust. However, that impact was distorted with other variables when tested in multiple linear regression. Thus, knowledge was ruled out from being a unique contributor to attitudes. The impact was said to be included in experience since it is a prerequisite and, ultimately, a part of it. Knowledge represents the actual information a person possesses about the Internet and about crowdfunding to be able to maneuver their way in the crowdfunding platform/website. Thorough knowledge can be useful when viewing and funding projects but also in later stages of the process (receiving feedback, asking questions, keeping up with the project progress, and the reward delivery process). Regression analysis gave a positive impact of this variable agreeing with the outcome of Vergara (2015) where individuals showed that they need a sufficient deal of information and knowledge before actually participating. The correlation between the two variables (knowledge and attitudes) was a positive one but a rather weak one compared to enthusiasm and trust.

\section{Conclusion}

\subsection{Implications \& Recommendations}

The research provides important findings regarding crowdfunding and individual attitudes toward participating in it. However, the real value is in how findings from the research can be practically applied to reap actual benefits. This paper appeals, first, to entrepreneurs who are longing to start their businesses and are struggling to acquire needed capital. It proposes that entrepreneurs can resort to crowdfunding as a different and unique method of financing that is gaining a lot of popularity and success in the world. Thorough definitions and information are provided in this reading in regard of details of crowdfunding that could be used as a base for understanding crowdfunding and adopting it as a funding mechanism. Second, results of this study benefit entrepreneurs who are considering crowdfunding as a method of financing but do not know how to actually get people to crowdfund. These entrepreneurs, thus, should consider the 4 elements in the conceptual model that are said to influence attitudes and work on each to target the right people and inspire them to participate. This involves targeting groups that are related to the subject and presenting the project from their point of view. This also includes communicating measures of security that the crowdfunding platform offers as well as their own potential as entrepreneurs to improve trust. In addition, entrepreneurs should target those with the needed knowledge and experience who will be more prone to take action or promote knowledge and experience in the groups lacking it to positively shape their attitudes toward the specified project. Thirdly, crowdfunding platforms who make profits from successfully funded projects could draw value from this research by gaining practical knowledge on the status of crowdfunding in Lebanon where there is low awareness of the topic in general and should take measures on how to improve it and bring it to the forefront of the Lebanese attention. Thus, these platforms have the benefit of helping entrepreneurs succeed in bringing their projects to life. Furthermore, efforts should be made to improve attitudes of the people toward this method of funding and their actual intentions to crowdfund. This can be achieved by improving security measures and communicating the safety the process involves. Communicating the payment process and how the transactions are handled safely can go a long way. Another thing to take into consideration is how personal information is protected and using the crowdfunding platform is safe and secure. Moreover, since awareness is low and understanding is below needed, crowdfunding platforms should promote campaigns to teach people about crowdfunding and how it works to increase their awareness and knowledge and propel any misconceptions some might have about the idea. Finally, since this new "trend" in Lebanon is actually a well-established funding method in many parts of the world which has benefited huge numbers of entrepreneurs, it should be increasingly educated and learned especially in learning institutions. This calls for the inclusion of crowdfunding as a funding mechanism in the curriculums in business management and finance and educating future entrepreneurs and potential funders about it.

\subsection{Research Limitations}

The research relied mostly on a virtual snowball sampling technique which is a sampling method that relies on the Internet where individuals fill out the survey and forward it to others who also forward it to others. Thus, the 
number of respondents gradually increases like a rolling snowball. This technique was the best-fit since for an exploratory study in Lebanon where the sample must contain individuals from all over Lebanon, social media and the Internet were the most appropriate way to reach rural areas such as South of Lebanon, North of Lebanon, and Beqaa. This is a limitation since the dynamics involved could threaten the generalizability of the results since the survey might reach only similar individuals. Moreover, the response rate could not be identified since a number of individuals were forwarding to others via social media.

\subsection{Suggestions for Future Research}

The research can be supported with a qualitative exploratory study that handles the outcome and findings obtained and further explains them to be applied more practically. The analysis of results and discussion of findings proposed that two variables might be the main variables (enthusiasm and trust) and two can be supporting variables (knowledge and experience). This idea, which is still a proposition in this paper, can be tested and researched more for possible changes in the conceptual model and confirmation or disconfirmation of it.

\section{References}

Agrawal, A., Catalini, C., \& Goldfarb, A. (2011). Friends, Family, and the Flat World: The Geography of Crowdfunding. NET Institute Working Paper, 10(8), 2-12. https://doi.org/10.3386/w16820

Alegre, I., \& Moleskis, M. (2016). Crowdfunding: a Review and Research Agenda. Working paper, IESE Business School- University of Navarra, Spain. pp. 18-30. https://doi.org/10.2139/ssrn.2900921_

AlHussaini, W., \& Hill, S. (2017). Global Entrepreneurship Monitor: National Report Lebanon. Retrieved from https://www.gemconsortium.org/file/open?fileId=50046

Bartlett, M. S. (1937). Properties of Sufficiency and Statistical Tests. Proceedings of the Royal Statistical Society, 160(901). https://doi.org/10.1098/rspa.1937.0109

Belleflame, P., Lambert, A., \& Schwienbacher, A. (2011). Crowdfunding: Tapping the Right Crowd. Journal of Business Venturing, 29, 2-21. https://doi.org/10.2139/ssrn.1836873

Brabham, D. C. (2008). Moving the Crowd at iStockphoto: The Composition of the Crowd and Motivations for Participation in a Crowdsourcing Application. First Monday, 13(6). https://doi.org/10.5210/fm.v13i6.2159

Breckler, S. J. (1985). Empirical Validation of Affect, Behavior, and Cognition as Distinct Components of Attitude. Journal of Personality and Social Psychology, 47, 1191-1205. https://doi.org/10.1037/0022-3514.47.6.1191

Carmines, E. G., \& Zeller, R. A. (1979). Reliability and Validity Assessment. SAGE Publications, Newbury Park, CA. https://doi.org/10.4135/9781412985642

Cronbach, L. J. (1951). Coefficient Alpha and the Internal Structure of Tests. Psychometrika, 16, 297-334. https://doi.org/10.1007/BF02310555

Dehling, S. (2013). Crowdfunding-A Multifaceted Phenomenon. School of Management and Governance, University of Twente, Netherlands. pp. 9. Retrieved from https://essay.utwente.nl/64436/1/Master_Thesis_SebastianDehling.pdf

El-Amine, Y. (2017). As E-commerce Slowly Grows in Region, Lebanon Lags Behind. Annahar, May $3^{\text {rd }}, 2017$.

Filion, L. (2011). Defining the Entrepreneur. World Encyclopedia of Entrepreneurship. pp. 41-52.

Gerber, E. M., Hui, J. S., \& Kuo, P. Y. (2012). Crowdfunding: Why People Are Motivated to Post and Fund Projects on Crowdfunding Platforms. Computer Supported Cooperative Work Workshop on Design, Influence, and Social Technologies: Techniques, Impacts and Ethics. pp. 5-7.

Ghauri, P., \& Gronhaug, K. (2005). Research Methods in Business Studies. Harlow, Financial Times, Prentice Hall.

Howe, J. (2008). Crowdsourcing: Why the Power of the Crowd is Driving the Future of Business. Crown Publishing Group, New York.

Inventis. (2014). Lebanon SME Strategy, a Roadmap to 2020. Ministry of Economy and Trade. pp. 1-15. Retrieved from http://www.economy.gov.lb/public/uploads/files/6833_5879_4642.pdf

Kaburi, S. N., Mobegi, V. O., Kombo, A., Omari, A., \& Sewe, T. (2012). Entrepreneurship Challenges in Developing Economies: A Case of Kenyan Economy. International Journal of Arts and Commerce, pp: 442.

Kaiser, H. F., \& Rice, J. (1974). Little Jiffy, Mark IV. Educational and Psychological Measurement, 34, 111-117. https://doi.org/10.1177/001316447403400115 
Kraus, S., Richter, C., Brem, A., Cheng, C. F., \& Chang, M. L. (2013). Strategies for Reward-Based Crowdfunding Campaigns. Journal of Innovation \& Knowledge, 1, 15.

Kuppuswamy, V., \& Bayus, B. (2013). Crowdfunding Creative Ideas: The Dynamics of Project Backers in Kickstarter. Entrepreneurship and Marketing e-Journal, 8-23. https://doi.org/10.2139/ssrn.2234765

Kuti, M., \& Madarasz, G. (2014). Crowdfunding. Public Finance Quarterly, 3, 355-363.

Legas, H. (2015). Challenges to Entrepreneurial Success in Sub-Saharan Africa: A Comparative Perspective. European Journal of Business and Management, 7(11), 25-30.

Ministry of Economy and Trade. (2013). Challenges facing the Lebanese SME Sector. pp: 13-14. Retrieved from https://www.economy.gov.lb/public/uploads/files/8618_1911_5908.pdf

Ministry of Economy and Trade. (2014). What's in Lebanon for SMEs? pp: 18-19 Retrieved from https://www.economy.gov.lb/public/uploads/files/1517_7355_9101.pdf

Mollick, E. R. (2013). Dynamics of Crowdfunding: an Exploratory Study. Journal of Business Venturing, 29, 1-12. https://doi.org/10.1016/j.jbusvent.2013.06.005

Moon, Y., \& Hwang, J. (2018). Crowdfunding as an Alternative Means for Funding Sustainable Appropriate Technology: Acceptance Determinants of Backers. Sustainability, 10(5), 7-15. https://doi.org/10.3390/su10051456

Morduch, J. (1999). The Microfinance Promise. Journal of Economic Literature, 1570-1573. https://doi.org/10.1257/jel.37.4.1569

Noyes, K. (2014). Why Investors are Pouring Millions into Crowdfunding. Fortune, New York. Retrieved from https://fortune.com/2014/04/17/why-investors-are-pouring-millions-into-crowdfunding/

Oxera. (2015). Crowdfunding from an Investor Perspective. European Union, pp. 2-65.

Poetz, M. K., \& Schreier, M. (2012). The Value of Crowdsourcing: Can Users Really Compete with Professionals in Generating New Product Ideas? Journal of Product Innovation Management, 29, 5. https://doi.org/10.1111/j.1540-5885.2011.00893.x

Salleh, F. H. M., Zainudin, S., \& Arif, S. M. (2017). Multiple Linear Regression for Reconstruction of Gene Regulatory Networks in Solving Cascade Error Problems. Advances in Bioinformatics, 2017, 1-15. https://doi.org/10.1155/2017/4827171

Sardouk, A., \& Dorant, C. (2015). Market Challenges Faced by Multinational Corporations in Frontier Markets: The Case of Lebanon. Retrieved from http://www.diva-portal.org/smash/get/diva2:824677/FULLTEXT01.pdf

Scarborough, N. M. (2011). Essentials of Entrepreneurship and Small Business Management. Pearson, $\left(6^{\text {th }}\right.$ ed.), pp. 20-22, 51-52.

Schwienbacher, A., \& Larralde, B. (2010). Crowdfunding of Small Entrepreneurial Ventures. Handbook of Entrepreneurial Finance (Oxford University Press). pp. 4-19. https://doi.org/10.2139/ssrn.1699183

Surowiecki, J. (2006). The Wisdom of Crowds: Why the Many are Smarter than the Few and How Collective Wisdom Shapes Business, Economies, Societies, and Nations. Personnel Psychology, 59(4), 982-985. https://doi.org/10.1111/j.1744-6570.2006.00060_10.x

Vergara, R. (2015). Awareness and Attitudes towards Crowdfunding in the Philippines. 9th Global Business Conference, 1, 3-5. Retrieved from

https://www.researchgate.net/publication/303860133_Awareness_and_Attitudes_Towards_Crowdfunding_i n_the_Philippines/download

Whitley, B. E. (2002). Principals of Research and Behavioral Science. Boston, McGraw-Hill.

World Bank. (2013). Crowdfunding's Potential for the Developing World. InfoDev, Finance and Private Sector Development Department, Washington, DC. Retrieved from https://openknowledge.worldbank.org/handle/10986/17626_

\section{Copyrights}

Copyright for this article is retained by the author(s), with first publication rights granted to the journal.

This is an open-access article distributed under the terms and conditions of the Creative Commons Attribution license (http://creativecommons.org/licenses/by/4.0/). 